\title{
Capturing spatial effects, technology interactions, and uncertainty in urban energy and carbon models: retrofitting Newcastle as a case-study
}

\author{
James Keirstead $^{\mathrm{a}, *}$, Carlos Calderon ${ }^{\mathrm{b}}$ \\ ${ }^{a}$ Dept of Civil \& Environmental Engineering, Imperial College \\ London, UK, $S W^{r}$ 2AZ \\ ${ }^{b}$ School of Architecture Planning $\&$ Landscape, Newcastle University \\ Newcastle upon Tyne, UK, NE1 7RU
}

\begin{abstract}
Local authorities often rely upon urban energy and carbon modelling tools to develop mitigation policies and strategies that will deliver reductions in greenhouse gas emissions. In this paper the UK example of Newcastle-uponTyne is used to critique current practice, noting that important features of urban energy systems are often omitted by bottom-up tools including interactions between technologies, spatial disaggregation of demand, and the ability to pursue over-arching policy goals like cost minimization. An alternative optimization-based approach is then described and applied to the Newcastle case, at the scale of both the whole city and the South Heaton district, and using Monte Carlo techniques to address policy uncertainty. The results show that this new method can help policy makers draw more robust policy conclusions, sensitive to spatial variations in energy demand and capturing the interactions between developments in the national energy system and local policy options. Further work should focus on improving our understanding of local building stocks and energy demands so as to better assess the potential of new technologies and policies.
\end{abstract}

\footnotetext{
${ }^{*}$ Corresponding author. Tel: +44 (0)207 5946010.

Email addresses: j.keirstead@imperial.ac.uk (James Keirstead), carlos.calderon@ncl.ac.uk (Carlos Calderon)
} 
Key words: urban energy systems, optimization, retrofit

\section{Introduction}

The IPCC Fourth Assessment Report concluded that "anthropogenic warming over the last three decades has likely had a discernible influence at the global scale on observed changes in many physical and biological systems" (IPCC, 2007, p. 50). It has been shown that greenhouse gas (GHG) emissions resulting from the provision of energy services have contributed significantly to the historic increase in atmospheric GHG concentrations (Corfee-Morlot et al., 2008) and, furthermore, approximately $71 \%$ of global energy-related greenhouse gas emissions can be attributed to urban areas (IEA, 2008). Consequently, the development of urban energy services over the coming decades is intrinsically linked to the Earth's climate and the vulnerability of human society to climate change.

It is now accepted that cities can be effective agents of change and centres of innovation to address climate issues (Dawson, 2007). Indeed, a growing number of cities have begun to add GHG emission targets to city policy objectives and many are working together in transnational networks to strengthen emissions reduction efforts (Bintliff et al., 2007; Bulkeley and Betsill, 2005; Betsill and Bulkeley, 2007; C40 Cities, 2011).

Within the UK, the landmark analysis of the economics of climate change presented in the Stern report (Stern, 2006) and the legal framework subsequently developed in the Climate Change Act (UK Government, 2008) have set stringent carbon targets (i.e. an $80 \%$ reduction in GHG emissions by 2050) and made the case for changes in cities' built environment and associated energy systems (e.g. HM Government, 2009). Thus, a major area of research is how to manage the decarbonization transition of the nation's urban built environment over the next four decades, particularly through local action where local authorities act as a primary conduit for the delivery 
of nationally-established climate change policy goals.

A number of research groups have begun bridging the gaps between science and policy in urban carbon management by developing a suite of analytical tools and procedures that help local governments assess their unique situation and select appropriate solutions (e.g. Dhakal and Shrestha, 2010; Keirstead and Schulz, 2010). This suite is what we call urban energy and climate change modelling, a nascent field of scientific inquiry that has the potential to provide vital support for evidence-based approaches to low carbon urban transitions. Specifically, these tools help to estimate a GHG emissions baseline at a point in time and to quantify the impact that technological interventions could have on the overall GHG footprint of a city.

In this paper, we examine how such modelling tools can be used to assist urban energy and climate policy. Working with Newcastle City Council in the UK, we assess current modelling practice and apply a new modelling tool to Newcastle's climate change and energy strategy, illustrating new features that improve a local authority's ability to plan detailed energy system interventions. The paper proceeds as follows. In Section 2, the case study is introduced, highlighting the research motivation and overall goals. Section 3 discusses the methodology, examining current modelling approaches and the new features of our model. In section 4 we present the results before finally reviewing the findings and outlining a number of recommendations.

\section{Case study background}

\subsection{Motivation}

Newcastle City Council (NCC) is one of a small number of UK local authorities (LAs) leading the way on energy and carbon reduction policies via area-based carbon emission reductions strategies. Area-based approaches were initially suggested by Shackley et al. (2002, p. 48). In their report, they highlighted that "one-off decisions by major energy users, for exam- 
ple to invest in more efficient technologies, or to move to $100 \%$ renewablysourced energy, can make a significant impact upon local to regional GHG emissions. Likewise, national or even international-level activities by the private or public sectors... will have a large impact on local to regional emissions." An area-based methodology thus needs to establish to what extent a spatially-referenced emissions target (i.e. for a city or neighbourhood) can be met through local actions or initiatives elsewhere, and to develop subsequent emissions inventories and mitigation activities. An area-based project requires the use of best-practice tools and methodologies, as well as technical guidance from energy researchers and consultants. Our study aims to improve best-practice for area-based mitigation projects.

'Mitigation' refers to the reduction of GHG emissions by reducing energy use (energy demand) and/or by producing and using cleaner energy sources (energy supply). Such measures are typically identified for specific sectors such as the building stock (e.g. improve energy efficiency in new and existing buildings, the use and generation of renewable or low carbon energy supplies), transport (e.g. reduced travel, car use, reducing food/product miles), and land use (e.g. promoting carbon sinks, reducing the amount of biodegradable waste in landfills). Our conversations with Newcastle's climate change team highlighted that the current priority is mitigating the climate change impact of the building stock.

\subsection{Policy background}

In recent years, NCC has surveyed over 70,000 homes and installed energy efficiency measures such as loft and cavity insulation in over 45,000. These measured were delivered via a Warmzone partnership, an area-based delivery model considered by many UK local authorities to be the most effective mechanism in securing large-scale delivery. With this model, energy utility companies fund area schemes and meet their obligations under the government's Carbon Emissions Reduction Target policy (which requires 
domestic energy suppliers to make household $\mathrm{CO}_{2}$ savings by promoting the adoption of low carbon technologies). The local authority, on the other hand, gets high levels of cost-effective measures installed, which helps to alleviate fuel poverty and reduce carbon emissions. Moreover the partnership creates jobs directly through their delivery contractors. Such schemes typically address "low hanging fruit" first, with cavity and loft insulation as the most popular measures.

New funding initiatives and bodies are being created in the UK to aid local authorities with their building stock mitigation strategies. For example, the Department of Energy and Climate Change (DECC) sees on-site smallscale renewables and low carbon technologies as a key part of future urban energy systems as outlined in its recent microgeneration strategy (DECC, 2011a, p. 45). LAs are therefore beginning to explore how these technologies might fit within their carbon and energy strategies in order to develop, implement and deliver area-based schemes for low carbon energy communities.

These initiatives, however, rely upon an evidence-based approach and the work presented here intends to support that process. It has the potential to be widely used by LAs, enabling them to explain the rationale behind a decision to promote decentralized low and zero carbon renewable sources of energy, as well as to offer developers specific local information and knowledge about what resources are available through a detailed feasibility study for renewable and low carbon energy community schemes. For example, Newcastle has one major district heating scheme based in the Byker district, servicing almost 1800 properties plus a further 47 smaller group and sheltered schemes. The Council is currently investigating the potential use of district or community energy schemes in other areas of the city. The Council's Energy Strategy commits the authority to investigate the feasibility of creating community energy schemes, possibly through an energy service company as a means of contributing to both carbon reduction and 
affordable warmth. Such decisions require critical appraisal of evidence.

\subsection{Current modelling practice and shortcomings}

To support its work in this area, NCC has adopted a tool known as VantagePoint and used it at various stages of the policy cycle (NCC, 2011; Carbon Descent, 2012). In fact, VantagePoint was selected as the preferred tool by all North East England councils who signed up to the Covenant of Mayors initiative, an EU initiative by which all LAs commit themselves to producing a Sustainable Energy Action Plan (SEAP). The North East was the first UK region in which all LAs followed a "normalized" methodology for the development of their SEAPs. VantagePoint is designed to help local authorities develop climate mitigation strategies. Users select from a range of policy interventions (including energy efficiency measures, low carbon technologies, behavioural changes, transport-related measures, and greening of the electricity grid) and iteratively develop a technology mix that meets a specified emissions target. The scenario is then adjusted by refining priorities for implementing measures and the outcome of the process is an action plan to be interpreted by the Local Authority.

The Newcastle experience suggests that, although this type of tool has been useful to understand the overall carbon picture, it has several shortcomings. Specifically it is unable to account for the interactions between technologies, it uses a highly-aggregate view of energy consumption variations in time and space, it provides limited guidance on the creation of criteria-based scenarios (e.g. minimum cost), and it is difficult to add important constraints on feasible technology mixes such as limitations on installation rates of key technologies. Also when used over longer periods (e.g. in pursuit of 2050 targets), VantagePoint offers only a single view of the future and users must manually run new scenarios to assess alternative futures. 


\subsection{Policy development challenges}

The above methodological issues have direct implications for the policies that local authorities choose to put into place. The primary question is to understand how local and national policies might work together over long periods. For example, a local authority may be interested in the tradeoffs and relative timing of deploying local renewables versus the greening of the national electricity grid. An appropriate decision support tool should provide guidance as to which local energy technologies are cost-effective given other developments in the energy system. Similarly there are questions about the sequential deployment of technologies. Current thinking suggests that all energy efficiency measures should be exploited before renewables and other low carbon technologies are considered. If so, it is important to understand the relative penetration rates of energy efficiency measures versus other interventions and likewise, the potential for these technologies will depend on an understanding of spatial variations in building type and energy demands. Local authorities therefore need more sophisticated urban energy and carbon modelling tools to develop appropriate responses to the challenge.

NCC is aware of these challenges and has highlighted a number of outstanding questions that affect their mitigation policy decisions. With this in mind, we have developed a modelling tool to answer the following issues:

- How does current modelling practice compare with alternative methodologies, and how might other approaches inform the development of urban energy and carbon policy?

- What is the impact of uncertainties in long-term policy development (i.e. 2010-2050)? Specifically:

- What is the role of local renewable technologies within Newcastle's retrofit strategy, i.e. as part of the wider installation of mit- 
igation technology measures in the existing building stock?

- What are the required build rates for domestic and commercial retrofits in Newcastle?

- What is the impact of spatially-disaggregated urban energy modelling on policy decisions?

\section{Methodology}

This section evaluates existing urban energy system models in light of NCC's goals. It is suggested that a new modelling framework is needed to capture salient details of the energy system, and the resulting TURN model is presented. We then discuss the input data and structure of the analysis performed.

\subsection{Existing urban energy models}

A review of the literature suggests that there are five main types of "urban energy system" model, differing in their scope and disciplinary approach (see Keirstead et al., accepted, for a longer review). First, there are tools that focus on the urban climate and its impacts on energy consumption, primarily in buildings (e.g. Kikegawa et al., 2006; Mavrogianni et al., 2011). Secondly there are models that examine building energy consumption in detail, for example by simulating their thermal behaviour or the effects of different ventilation strategies (Kampf and Robinson, 2007; Wei et al., 2010). Technology-specific simulation tools can also be found, often used to improve the design of urban renewable energy technologies (e.g. Celik et al., 2007; Taherian et al., 2011). These models contribute to the design and operation of individual components within an urban energy system, but we wish to focus on the city as a whole.

Policy assessment models are one example of this broader approach. These high-level tools describe the effect of policies on urban energy con- 
sumption, such as planning decisions about density and urban form (e.g. Shimoda et al., 2010; Pohekar, 2004). Such assessments can be both retrospective (i.e. trying to explain observed differences in energy consumption), or prospective (i.e. assessing how policy targets might be achieved). However for NCC, many of the energy policy questions being considered require a more robust analysis of these issues. For example, a key question noted above was the relative merits of local renewable energy generation versus the greening of the national electricity grid. Since "renewables" includes a range of technologies (both heat and electricity generating), and the performance of the grid changes over time, a modelling framework to evaluate the overall carbon impacts of urban energy consumption must be able to evaluate trade-offs between multiple technologies over multiple time periods. Many relevant technologies, such as combined heat and power connected to a district heating network, also have significant spatial dimensions that must be accounted for when assessing costs.

This highlights the need for the final category of urban energy system model, the system design model. These tools are optimization-based models that select a combination of technologies in order to meet a specific goal, subject to constraints (e.g. minimizing total system cost while complying with a carbon reduction target). Examples of such models include Girardin et al. (2010), Sugihara et al. (2004), and Bruckner et al. (2003). Our model is of this type and is discussed in the next section.

\subsection{The TURN model}

The model used for this paper is called TURN (Technologies and Urban Resource Networks). Its goal is to create a strategic energy plan for an urban area, taking into account spatial and temporal variations in energy service demand.

As input, users specify energy service demands, varying in space and time, as well as the available energy supply technologies and fuels. Related 
issues, such as the impacts of population or economic growth on energy demand, must be modelled separately and these results then imported into the TURN model. In previous work, the temporal dimension has typically been two periods, representing for example average/peak or summer/winter patterns of demand. Otherwise, the analysis is static and tries to identify the lowest cost energy system configuration for a single planning year (e.g. Keirstead et al., in press). However in addition to these within period temporal variations, the current case study also asks what is the best energy strategy over a planning horizon of multiple decades. As a result, the model's equations have been altered to incorporate a new temporal variable, the planning year $y$.

The model's primary equation is a resource balance:

$$
S_{r, i, t, y}=P_{r, i, t, y}+I_{r, i, t, y}-E_{r, i, t, y}+Q_{r, i, t, y}-D_{r, i, t, y}
$$

where $P_{r, i, t, y}$ is the production of resource $r$ in zone $i$ at time $t$ within year $y$, $I$ and $E$ are resource imports and exports across the city boundary, $Q$ is the net resource flow within the city (e.g. flows to and from neighbouring zones to zone $i$ ), $D$ is the resource demand, and $S$ is the surplus, all over the same indices. Resources include both input fuels (e.g. natural gas), intermediate products (e.g. district heating), and end-services (e.g. space heating). The model therefore has a number of available strategies to meet the user-specific energy service demands including local resource production, transportation, imports, and storage.

Imports and exports are controlled by a series of binary variables that specify whether or not a resource is imported to a given zone, and similar variables control the in-city resource flows $Q$. Production of a resource is determined by the number of discrete technologies installed in a given zone and their associated production rates, the value of both variables being selected by the model. Since NCC's strategy does not consider storage, we have omitted this from the present analysis by setting the surplus variable 
$S=0$ for all indices. The combination of integer and continuous decision variables mean that the model can be described as a mixed-integer linear programme.

The objective of the model is to minimize the total cost of the energy system, including capital and operating costs, discounted to a 2008 net present value. As the goal is to study long-term pathways, we have not included subsidies and other policy support options as these are likely to change over the forecast horizon. This goal is subject to a number of constraints that capture key features of urban energy systems. For example, each household within the city must have at least one heat producing technology such as a boiler or heat exchanger connected to a district energy system. Without such a constraint, the resource balance described above could be satisfied by sharing the output of larger technologies amongst all households in a single zone (e.g. a single $1000 \mathrm{~kW}$ boiler running at 10\%, rather than $10 \mathrm{~kW}$ boilers in each of ten households). There are also network continuity constraints to ensure that resource transportation can only occur if an appropriate network infrastructure exists (e.g. a district heat network to move hot water).

In addition to the model's basic structure (see Samsatli et al., submitted, for further details), additional constraints were needed to capture the multiple planning periods. The first is a continuity constraint, to ensure that the number of processes $p$ operating in any given zone and time pe$\operatorname{riod}\left(N P O_{p, i, y}\right)$ is equal to the currently installed processes plus any net purchases, where $N P D$ and $N P P$ represent process demolition and purchase respectively:

$$
N P O_{p, i, y}=N P O_{p, i, y-1}+N P P_{p, i, y}-N P D_{p, i, y}
$$

The second constraint is a carbon constraint, assuming that the total emissions from Newcastle in year $y\left(C_{y}\right)$ must comply with nationally specified carbon budgets. Baseline emissions for the first period $\left(C_{0}\right)$ were calculated using data from DECC (2011b) and the targets $\left(\Delta_{y}\right)$ specified based 
on Committee on Climate Change data (CCC, 2010).

$$
C_{y} \leq \Delta_{y} C_{0}
$$

Further constraints were added to simulate limits on the build rates of both domestic and commercial-scale technologies, and to ensure that domestic retrofit measures were appropriately applied; for example, a household could have solid-wall or cavity-wall insulation but not both.

\subsection{Data}

Demand data for electricity and space heating were taken from DECC (2011b) at the MLSOA and LLSOA ${ }^{1}$ levels (2008 data). Splits between summer and winter demands were estimated from degree day records for heating and National Grid profiles for electricity. These data allow the annual average demands provided by DECC to be allocated into consistent seasonal values; for example, for electricity, it is assumed that the summer demands are $84 \%$ of the annual total and winter demands $116 \%$. As the model requires energy service demands, not raw fuels, DECC gas demand data was converted into space heating at an assumed efficiency of 81\% (EST, 2011).

Table 1 lists the technologies considered by the analysis, representing both supply and demand side measures. These technologies were drawn from those listed in NCC's SEAP, omitting local wind energy technologies which are no longer of interest to the local council and adding existing heating technologies which are not considered in the SEAP. Within the model, each technology functions as a "black box" converting a set of input resources to output resources at some specified efficiency. For example, the condensing boiler burns $1.11 \mathrm{~kW}$ of gas to produce each $\mathrm{kW}$ of useful heat. The output

\footnotetext{
${ }^{1}$ Medium and lower-level super output areas are widely used geographies for UK local statistics (see ONS, 2011).
} 
rate of a given technology is bounded by both a minimum and maximum production capacity and is assumed to operate at constant efficiency between these values. Supply side technologies are also described by a capacity factor which accounts for variability in output due to either natural variation (e.g. for photovoltaics) or plant availability (e.g. maintenance outages for thermal plant).

\subsection{Analysis structure}

The analysis was divided into three steps. First, the model was calibrated with observed data for 2008 and these results used to define the starting conditions for further analyses. A related validation run was also performed to compare the results of the TURN model with an existing analysis performed by NCC using the VantagePoint model described above. In these simulations, a single zone was used to represent the entire city of Newcastle.

With the basic performance of the TURN model validated, the second step was to conduct a Monte Carlo simulation, again at the whole-city scale. The aim of these runs was to evaluate the impact of input parameter uncertainty when forecasting energy strategies over the long term (to 2050). The resulting sensitivity analysis helps to identify the parameters that are most important in determining the structure of the urban energy system.

Finally the model was applied to six LLSOA zones within the South Heaton district of Newcastle, again within a Monte Carlo framework. The goal of this analysis was to gain a better understanding of the impact of spatial disaggregation on the modelling of an urban energy strategy. In other words, what does an overall urban energy strategy look like when translated to the level of individual neighbourhoods?

Together these analyses demonstrate three innovative features compared to existing NCC modelling practice. First the analysis is performed at two scales, facilitating an assessment of the impact of spatial disaggregation on 


\begin{tabular}{|c|c|c|c|c|c|c|}
\hline Technology & $\begin{array}{l}\text { Capital } \\
\text { cost }(£)\end{array}$ & $\begin{array}{r}\text { Operational } \\
\text { cost }(£)\end{array}$ & $\begin{array}{r}\text { Max Capacity } \\
(\text { nameplate kW) }\end{array}$ & $\begin{array}{r}\text { Capacity } \\
\text { factor }\end{array}$ & Sector & Type \\
\hline \multicolumn{7}{|l|}{ Demand side measures } \\
\hline Behavioural change & 0 & 0 & $0.345^{*}$ & 1 & $\mathrm{D}$ & $\mathrm{O}$ \\
\hline Loft insulation & 200 & 0 & 0.558 & 1 & $\mathrm{D}$ & $\mathrm{EE}$ \\
\hline Double-glazing & 2000 & 0 & 0.264 & 1 & $\mathrm{D}$ & $\mathrm{EE}$ \\
\hline Cavity-wall insulation & 310 & 0 & 0.519 & 1 & $\mathrm{D}$ & $\mathrm{EE}$ \\
\hline Solid-wall insulation & 2300 & 0 & 0.944 & 1 & $\mathrm{D}$ & $\mathrm{EE}$ \\
\hline \multicolumn{7}{|l|}{ Supply side measures } \\
\hline Non-condensing boiler & 1000 & 50 & 24 & 0.95 & $\mathrm{D} / \mathrm{C}$ & $\mathrm{O}$ \\
\hline Condensing boiler & 1000 & 50 & 24 & 0.95 & $\mathrm{D} / \mathrm{C}$ & $\mathrm{O}$ \\
\hline Electric heater & 860 & 25 & 24 & 0.95 & $\mathrm{D} / \mathrm{C}$ & $\mathrm{O}$ \\
\hline Heat exchanger & 1000 & 50 & 24 & 0.95 & $\mathrm{D} / \mathrm{C}$ & $\mathrm{O}$ \\
\hline Air-source heat pump & 8000 & 50 & 24 & 0.90 & $\mathrm{D}$ & $\mathrm{RE}$ \\
\hline Ground-source heat pump & 11000 & 50 & 24 & 0.90 & $\mathrm{D}$ & $\mathrm{RE}$ \\
\hline Solar hot water & 2700 & 100 & $0.54^{* *}$ & 0.90 & $\mathrm{D}$ & $\mathrm{RE}$ \\
\hline Solar hot water & 11000 & 400 & $2.2^{* *}$ & 0.90 & $\mathrm{C}$ & $\mathrm{RE}$ \\
\hline Photovoltaics & 7500 & 30 & 2.5 & 0.083 & $\mathrm{D}$ & $\mathrm{RE}$ \\
\hline Photovoltaics & 27000 & 120 & 10 & 0.083 & $\mathrm{C}$ & $\mathrm{RE}$ \\
\hline Biomass boiler & 1100 & 70 & 24 & 0.90 & $\mathrm{D}$ & $\mathrm{RE}$ \\
\hline Biomass boiler & 275000 & 5000 & 100 & 0.55 & $\mathrm{C}$ & $\mathrm{RE}$ \\
\hline Building CHP (gas-fired) & 150000 & 2500 & 100 & 0.70 & $\mathrm{C}$ & $\mathrm{O}$ \\
\hline District CHP (gas-fired) & $6.7 \times 10^{6}$ & 4300 & 10000 & 0.67 & $\mathrm{O}$ & $\mathrm{O}$ \\
\hline Biomass CHP & $27.5 \times 10^{6}$ & 500000 & 10000 & 0.55 & $\mathrm{O}$ & $\mathrm{RE}$ \\
\hline
\end{tabular}

Table 1: Energy conversion technologies used in the analysis. Design parameters taken from Kannan et al. (2010) and author estimates. Capital costs amortized at $6 \%$ for 15 years for commercial technologies, and $10 \%$ for 10 years for domestic technologies. The capacity factor is defined as the ratio of a technology's annual output to its potential maximum output as described by the nameplate capacity. ${ }^{*}$ Behavioural change capacity corresponds to a $10 \%$ saving in heat demand, ${ }^{* *}$ Solar thermal capacity based on $10 \mathrm{~m}^{2}$ panels domestic, $40 \mathrm{~m}^{2}$ commercial. Sector: $\mathrm{D}=$ domestic, $\mathrm{C}=$ commercial, $\mathrm{O}=$ other. Type: $\mathrm{EE}=$ energy efficiency, $\mathrm{RE}=$ renewable energy, $\mathrm{O}=$ other. 
the choice of urban energy strategies. Second, the use of uncertainty and sensitivity analysis is integral to the identification of technology options which are robust under a range of futures. Finally, the model captures technology interactions within a constrained optimization framework. This means that the user does not have to make an explicit choice about individual technologies, but instead selects overall policy goals and constraints (e.g. minimizing cost and reaching a carbon target).

\section{Results}

\subsection{Calibration and validation}

To calibrate the model, the UK Home Energy Efficiency Database (HEED) was used to estimate the existing installations of domestic energy supply and efficiency measures such as boiler type, double-glazing, wall and loft insulation, and combined heat and power systems within the study area (EST, 2011). The corresponding decision variables in the optimization model were fixed with these values and the model run to calculate the overall greenhouse gas emissions. The results compare well to the equivalent National Indicator 186 emissions for Newcastle (end-user carbon dioxide emissions in the local area from the industrial, domestic and transport sector) (DECC, 2011c), after omitting emissions from road transport which are not considered here: 1.40 $\mathrm{Mt} \mathrm{CO}_{2 e}$ (modelled) versus 1.41 $\mathrm{Mt} \mathrm{CO}_{2 e}$ (NI 186).

With the 2008 initial conditions fixed, the model was then run to find the lowest cost energy system that would meet (or exceed) the Committee on Climate Change target of a 34\% emissions reduction by 2020 (relative to a 1990 baseline), assuming the same decarbonization of electricity from the national grid as described by the CCC (2010). NCC had previously used the VantagePoint model for this purpose and so by comparing the two sets of results, it is possible to validate the TURN model against another method. 
The results in Table 2 show that the TURN model reduces carbon emissions more quickly than the VantagePoint trajectory, giving 2020 emissions $16 \%$ below the original target. Table 3 shows the mix of technologies installed in the city by 2020 . The supply side of both solutions is broadly similar, although with more renewable energy generation technologies in the TURN solution, such as solar hot water and photovoltaics, and some district heating; this latter result includes an assumption that such a district heating system would require the construction of a $10 \mathrm{~km}$ district heating network. The demand side of both results highlights the importance of energy efficiency measures, although the TURN solution has selected a different mix of technologies.

\begin{tabular}{llrr}
\hline Source & Metric & $2005-2010$ & $2010-2020$ \\
& $\left(\mathrm{kt} \mathrm{CO}_{2 e}\right.$, end year $)$ & & \\
\hline VantagePoint & $\mathrm{CO}_{2}$ target & 1360 & 1170 \\
& $\mathrm{CO}_{2}$ modelled & 1400 & 1150 \\
TURN & $\mathrm{CO}_{2}$ modelled & 1090 & 980 \\
\hline
\end{tabular}

Table 2: Validation of the multi-period TURN model. VantagePoint data comes from NCC (2011).

These discrepancies can be explained largely by their respective methodologies, that is designing a solution with user preferences in technology mix versus an optimization solution based on cost minimization. A related issue is that the TURN model's objective function minimizes the cumulative cost of all energy system components over the study period. This effectively represents a societal cost, whereas in reality the energy system is the result of the decisions of multiple stakeholders with different preferences (utilities, households, local authorities), rather than an omniscient master planner. If these individuals made independent cost minimization decisions, the overall energy system would likely be different. Furthermore, the TURN model in- 


\begin{tabular}{|c|c|c|c|}
\hline \multirow[b]{2}{*}{ Technology } & \multirow[b]{2}{*}{ Unit } & \multicolumn{2}{|l|}{ Model } \\
\hline & & VantagePoint & TURN \\
\hline \multicolumn{4}{|l|}{ Demand side measures } \\
\hline Behavioural change & Homes & 111225 & 111225 \\
\hline Loft insulation & $"$ & 41000 & 47700 \\
\hline Double-glazing & $"$ & 20000 & 8000 \\
\hline Cavity-wall insulation & $"$ & 27000 & 14500 \\
\hline Solid-wall insulation & $"$ & 10000 & 47600 \\
\hline \multicolumn{4}{|l|}{ Supply side measures } \\
\hline Non-condensing boiler & Homes & $51200^{*}$ & 51200 \\
\hline Condensing boiler & $"$ & $55600^{*}$ & 56900 \\
\hline Electric heater & $"$ & $4500^{*}$ & - \\
\hline District heating & $"$ & - & 1000 \\
\hline Air-source heat pump & $"$ & - & - \\
\hline Ground-source heat pump & $"$ & 500 & - \\
\hline Solar hot water & $"$ & 5000 & 8000 \\
\hline Photovoltaics & $"$ & 3000 & 8000 \\
\hline Domestic biomass boiler & $"$ & 500 & 3000 \\
\hline Commercial biomass boiler & $\mathrm{MW}_{t h}$ & 1 & - \\
\hline Building CHP & $\mathrm{MW}_{e}$ & 15 & 5.3 \\
\hline
\end{tabular}

Table 3: A comparison of the 2020 energy system configurations for Newcastle, as projected by the VantagePoint and TURN models. The target is a $34 \%$ reduction in greenhouse gas emissions from 1990 to 2020 (equal to 20\% reduction versus VantagePoint's 2005 baseline). *Assumed no change since 2005, as not specified in VantagePoint analysis. 
cludes restrictions on the maximum level of certain technology installations based on HEED data; this feature is discussed further below. Nevertheless the calibration and validation have demonstrated that the TURN model can generate reasonable alternative energy system designs that are relevant to existing policy debates.

\subsection{Monte Carlo analysis}

In the near term, to 2020, most of the parameters in the model can be described with reasonable certainty. Costs of fuels and technologies may change but one might assume that such changes will be insignificant to the overall structure of the model solution and resulting energy system. However when looking at a longer forecasting horizon, for example to 2050, these uncertainties are harder to ignore. For instance Figure 1 shows the provision of demands for electricity and heat from different technologies to 2050. Here we have assumed that that final heat demand is constant in all periods, balancing an assumed increase in thermal comfort against a decrease in heating degree days due to climate change; in other words, in the absence of a full assessment of these effects (which is outside the scope of this paper), a no-change solution seems sensible. However many of the other parameters in the model are subject to known uncertainties that can be modelled more rigourously using Monte Carlo simulations; the results shown in Figure 1 were calculated only with the expected values of these inputs.

To prepare this analysis, seven model input parameters of interest were identified (table 4). The list is not exhaustive but represents the types of uncertainty that a decision-maker might face when planning an urban energy system. For example, project finance uncertainty is captured by the discount rate, inflation rate, and estimated cost of achieving a behavioural change in demand; changes in the physical constraints on the problem are represented by the growth rate of electricity demand and the potential build 


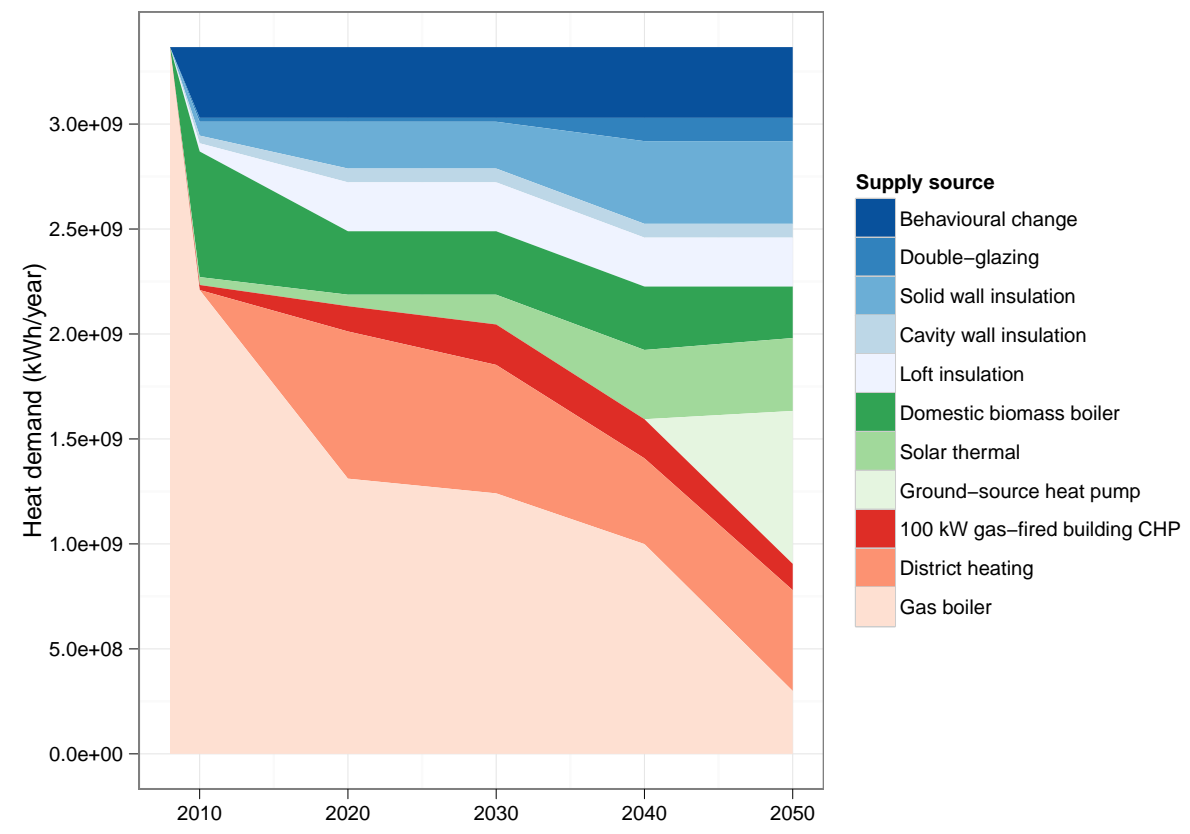

(a) Heat

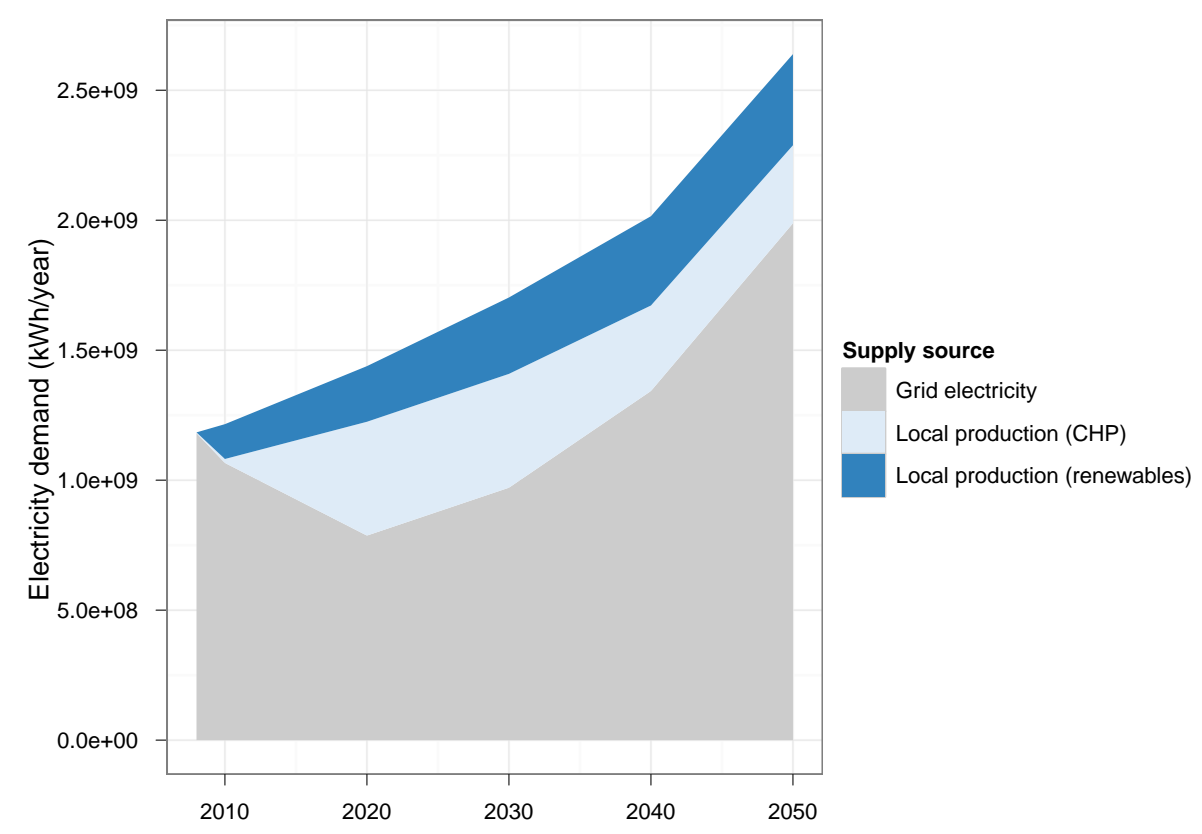

(b) Electricity

Figure 1: Provision of energy demand in the Newcastle whole-city case (2008-2050). Fossil-fuel sources are shown in red, renewable energy technologies in green, and efficiency measures in blue. In figure 1(a), the distridt9heating system consists of heat exchangers in individual dwellings powered by central CHP schemes. By 2050, $77 \%$ of this district heating is provided by gas-fired CHP units with the remainder coming from biomass CHP. 
rates in the domestic and commercial sectors; and the maximum CHP limit represents a policy constraint that might be affected by local decisions. In all cases, these are variables whose true value is unknown but the corresponding uncertainty can be expressed as a probability distribution using observed or best-guess data.

\begin{tabular}{|c|c|c|}
\hline Parameter & Distribution & Notes \\
\hline Discount rate & $U(3.5,10)$ & $\begin{array}{l}\% \text {, Treasury Green Book rate for large invest- } \\
\text { ments, through to a commercial threshold }\end{array}$ \\
\hline Inflation & $\Gamma(3.09,1.13)$ & $\begin{array}{l}\%, \Gamma \text { distribution fitted to historic UK data } \\
(1989-2010)\end{array}$ \\
\hline Electricity demand growth & $U(0,5)$ & $\begin{array}{l}\% \text {, based on Hong et al. (2009) estimated re- } \\
\text { bound effect. }\end{array}$ \\
\hline Build rate (domestic) & $T(2,10,20)$ & $\begin{array}{l}\text { Dwellings per day that can be retrofitted, based } \\
\text { on SEAP (i.e. technologies D in table 1). }\end{array}$ \\
\hline Build rate (commercial) & $T(1,10,20)$ & $\begin{array}{l}\text { Installations of commercial technologies per year, } \\
\text { based on SEAP (i.e. technologies C and O in ta- } \\
\text { ble 1). }\end{array}$ \\
\hline Behavioural change cost & $U(0,200)$ & $\begin{array}{l}£ \text { per household, cost of achieving a behavioural } \\
\text { change in demand, e.g. via an energy display } \\
\text { monitor }\end{array}$ \\
\hline Max. CHP output & $U(0,134)$ & $\begin{array}{l}\text { MW, compared to average } 2008 \text { electricity de- } \\
\text { mand of } 134 \mathrm{MW}\end{array}$ \\
\hline
\end{tabular}

Table 4: Description of parameter distributions for Monte Carlo uncertainty and sensitivity analyses. $U(\min , \max )=$ uniform distribution, $\Gamma(s, r)=$ Gamma distribution with given $(\mathrm{s})$ hape and $(\mathrm{r})$ ate parameters, $T(\min , \operatorname{mode}, \max )=$ triangular distribution.

Monte Carlos analyses can be run for several different purposes, such as describing the variability of a model's output under different assumptions (uncertainty analysis) or assessing how the variability of input parameters affects a model's output (sensitivity analysis). In this case, we sought to calculate the Sobol' first-order and total sensitivity indices. These metrics calculate the amount of variance in a given model output in response to variation in the input parameters, both on their own and through interactions with other variables. The analysis requires $n(p+2)$ model runs, with 
a suggested $n$ value of 500 and the number of parameters $p=7$ as described above (Saltelli et al., 2008). Therefore 4500 model runs were performed and sampling was done with a Sobol' quasi-random sequence to ensure efficient coverage of the parameter space.

An initial analysis of the results showed that $12.1 \%$ of the parameter combinations resulted in an infeasible model solution. By examining the distribution of the input parameters in the feasible and infeasible result sets, it was determined that growth in electricity demand was the key variable. When demand growth rates were above $4 \%$, there was a $99.6 \%$ chance of an infeasible solution versus a $90.8 \%$ chance of a feasible result when demand grew at less than $4 \%$ per annum. The corresponding distribution was therefore changed to $U(0,4) \%$ and the analysis run again; this led to only $0.20 \%$ infeasible solutions.

Four output variables of interest were identified: the cumulative energy system cost (i.e. the objective function value), the cumulative carbon emissions over the analysis period, the percentage of heat demand met by combined heat and power, and the percentage of total energy demands met by renewable energy generated within the city (e.g. all RE technologies in table 1 above). As figure 2 shows, the most important input variables differ depending on the output metric of interest. For example, the total system cost is affected primarily by the variability of growth in electricity demand and the discount rate, whereas for carbon emissions, the contribution of each variable is similar. The amount of heat provided by CHP within the optimal energy system is most sensitive to the maximum CHP output constraint (as expected) but also the growth in electricity demand. The share of total energy demand met by renewables is sensitive primarily to electricity demand growth. From a policy perspective, this means that, if a specific electricity demand growth target were selected (thereby narrowing the range of parameter uncertainty), then policy makers could have greater confidence 
as to the likely CHP and renewable energy fractions.

The simulation results were also used to answer two questions. First, what is the likely role of local renewable energy technologies in Newcastle's energy strategy? Figure 3 plots the contribution of renewable energy from the domestic and commercial sectors for all feasible model runs, including a constraint on the available area for each technology (e.g. roof space limitations for PV). It shows that domestic renewables have a significant role to play, accounting for approximately $23 \%$ of total energy demand by 2050 compared with a $2.4 \%$ contribution from the commercial sector (including district-scale biomass CHP). The dip in the share of total energy demand coming from domestic renewables, between 2010-2040, is due to the growing role of efficiency measures in meeting total demand.

The second question is what are the required build rates for measures in the domestic and commercial sectors in order to meet the targets? As discussed above, the growth in electricity demand must be kept under $4 \%$ per year to achieve the carbon reduction targets under the present assumptions; this reduces the number of infeasible results from $12.1 \%$ to $0.20 \%$ of model runs. A more relevant question is therefore, assuming that electricity demand growth can be kept below $4 \%$, what is the effect of build rates on key output variables? Figure 4 shows no distinct pattern. A linear regression was performed, suggesting that by increasing the maximum allowed domestic build rate by one dwelling per day, approximately $-0.11 \pm 0.02 \mathrm{Mt}^{\mathrm{CO}_{2 e}}$ could be saved over the 2008-2050 period $\left(r^{2}=0.043, p \ll 0.001\right)$. However given the low $r^{2}$ value, the conservative conclusion is that even modest rates will enable the overall carbon targets to be met, provided that electricity demand growth is below $4 \%$.

The related figure 5 gives the range of penetration levels for key domestic energy efficiency measures, as well as the maximum potential installation rate of each technology based on HEED (EST, 2011). The results indicate 


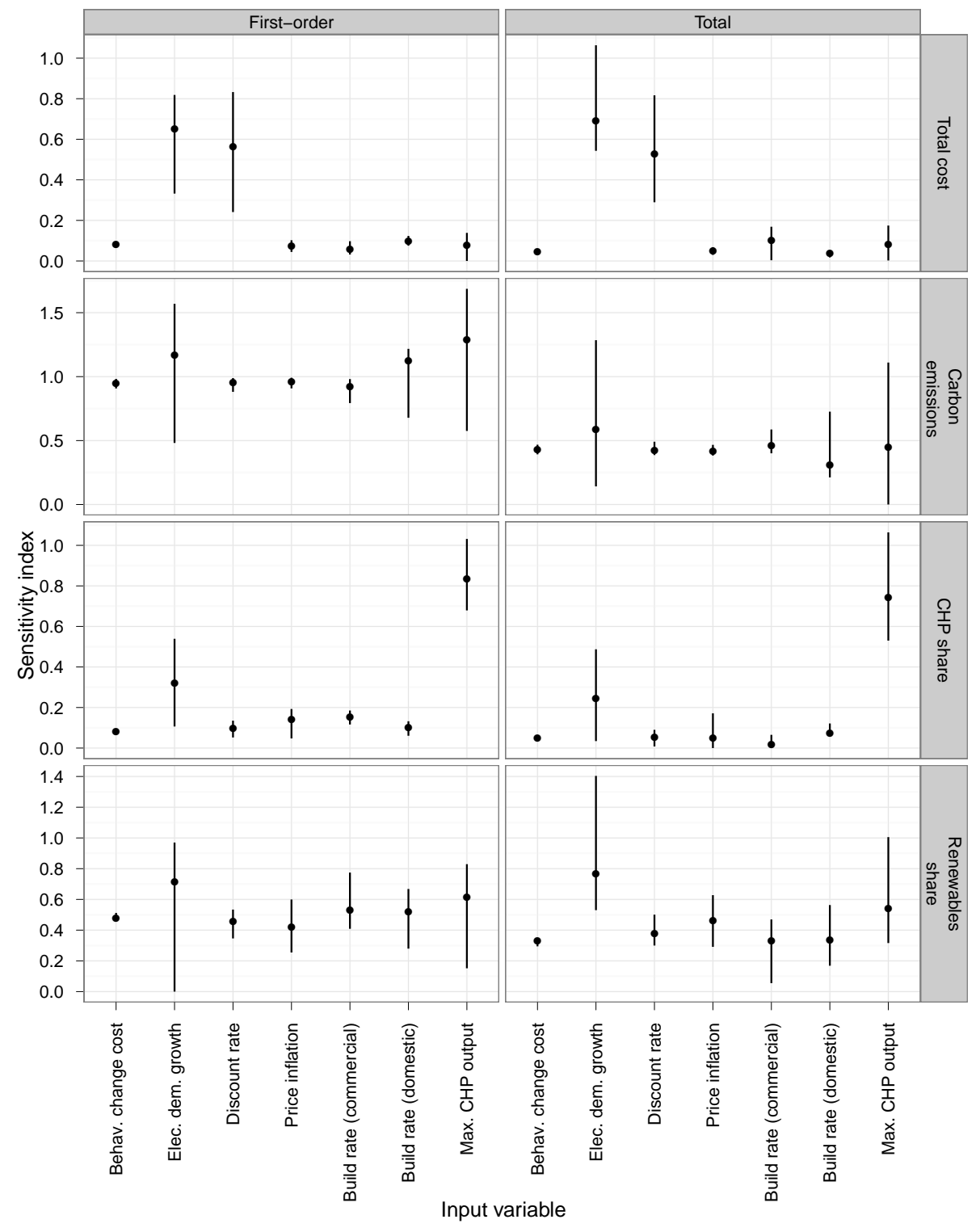

Figure 2: Sensitivity analysis results. First-order index values refer to the effect of the variability of a single input ( $\mathrm{x}$-axis) on the output of interest (y-axis), whereas the total index captures the effects of that parameter's variability on its own and through interactions with other variables. For example, in a simple model $y=f\left(x_{1}, x_{2}\right)$, the first-order index for $x_{1}$ would be the effects of $x_{1}$ on its own, whereas the total index would include the first-order effects of $x_{1}$ as well as its interactions with $x_{2}$. Error bars give $95 \%$ confidence intervals; note that sensitivity indices are dimensionless. 


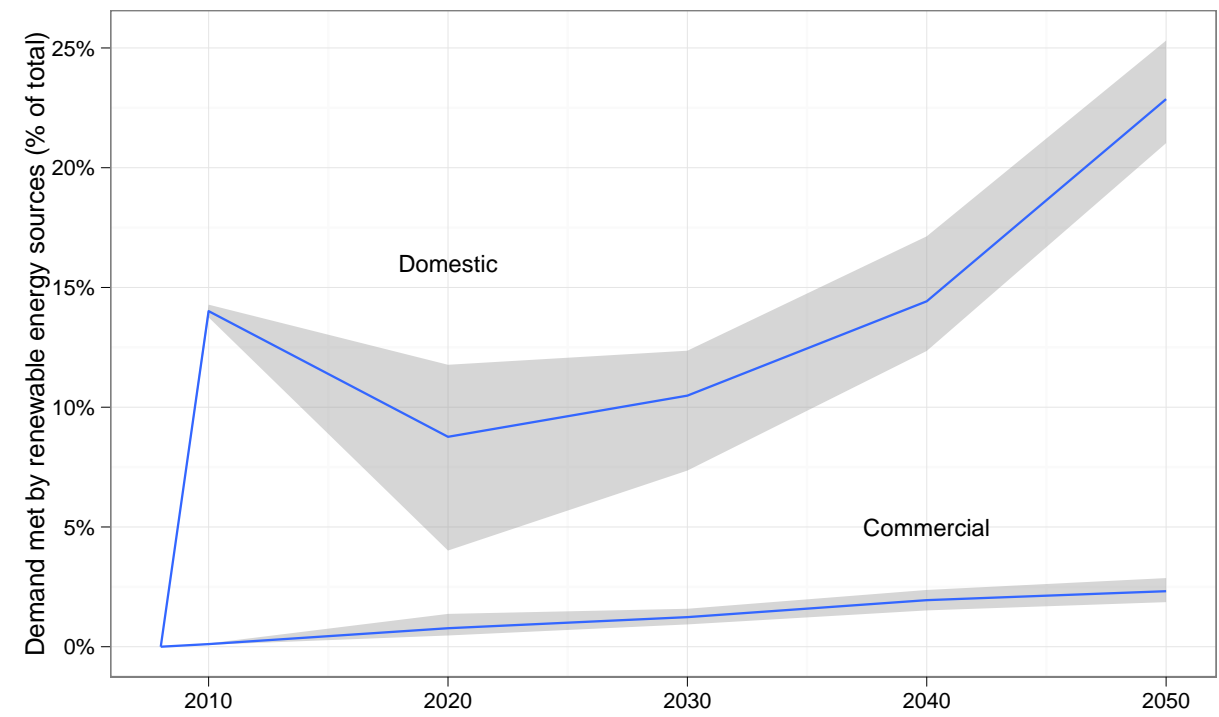

Figure 3: Growth of renewable energy in the domestic and commercial sectors as part of Newcastle's overall energy strategy. The shaded area represents the interquartile range and the line gives the median value.

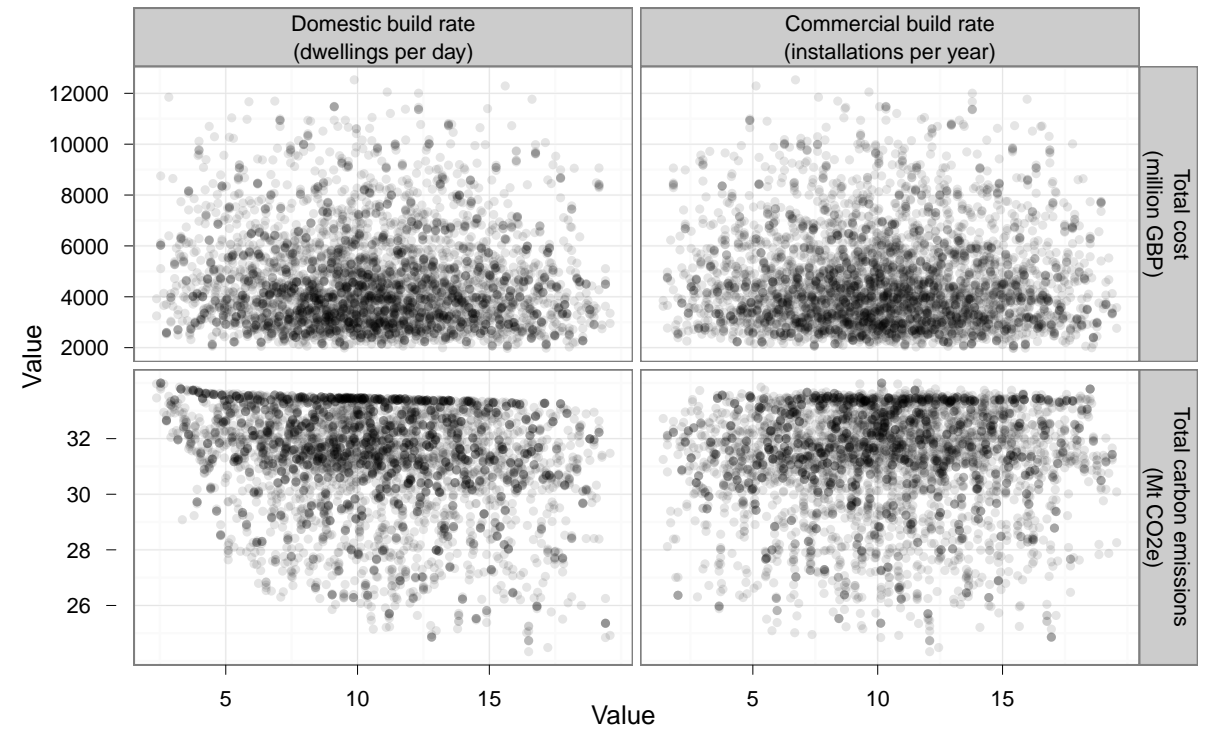

Figure 4: The effect of maximum rates of domestic and commercial installation measures on total system cost and cumulative carbon emissions. Each point represents one model run. 
full penetrations of loft insulation and cavity wall insulation by 2030, and solid wall insulation by 2040. While the rate of double-glazing installation does increase over the analysis period, the full $100 \%$ penetration level is not achieved. This reflects the relative cost of double-glazing against other retrofit and low carbon generation technologies. These rates of penetration are also highly dependent on the HEED data which describes both the current levels of efficiency measures and their maximum potential. We will return to this issue in the conclusion.

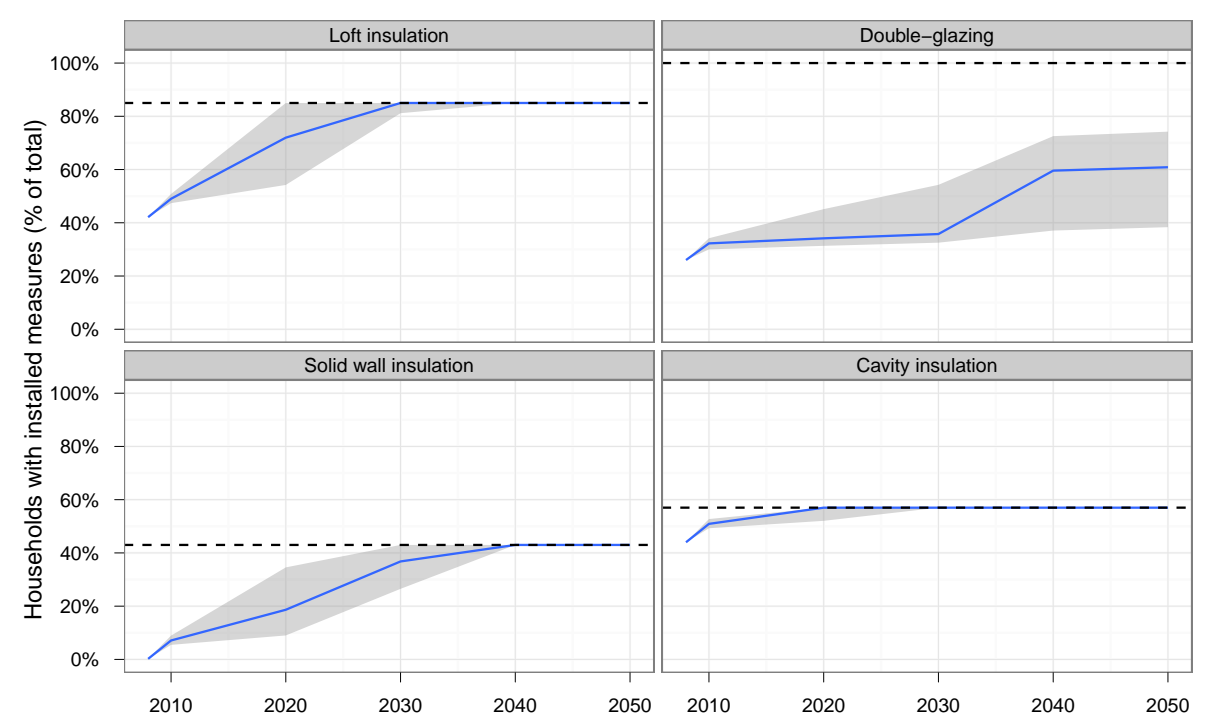

Figure 5: Penetration of domestic energy efficiency measures as part of Newcastle's overall energy strategy. The shaded area represents the interquartile range and the solid line gives the median value. The dotted line indicates the maximum potential installation rate, based on information about building types available in the HEED database.

This analysis of Newcastle's energy system, considering the city as a single geographic entity, provides a good sense of what general strategy the city should take to meet its carbon targets. As demonstrated by the feasibility analysis, the first priority is to control growth in electricity demand in order to ensure that targets can be met without an overly ambitious rate of energy 
efficiency or renewable energy installation. The second step is to pursue full installation of energy efficiency measures, particularly loft insulation, cavity wall insulation, and solid wall insulation; double-glazing is necessary for achieving the final 2050 targets, but installation rates accelerate mainly after 2030. Third, there must be a significant increase in low carbon generation within the city, achieved with a combination of district heating (with combined heat and power) and renewable energy technologies for both electricity and heating. Finally, to achieve the final 2050 target, the decarbonization of grid electricity is important with significant heat provision in 2050 from ground-source heat pumps.

\subsection{South Heaton}

As noted above, cities like Newcastle often create their energy and climate strategies at the scale of the entire city, owing to limited data availability and modelling tools. However this aggregate analysis necessarily simplifies aspects of energy system design, specifically removing spatial factors that might affect the relative preference for technologies such as combined heat and power. For example, we assumed that a $10 \mathrm{~km}$ network was part of the capital cost for CHP in the aggregate analysis above but a more accurate analysis would consider the specific location of heat loads and only build the necessary pipe connections. We therefore wished to explore how the results might vary if a specific part of the city was studied in greater detail. The six LLSOA zones that make up South Heaton were chosen for this purpose, an area representing $3.6 \%$ of Newcastle's total population (figure 6 ).

\subsubsection{Calibration and validation}

As before, a calibration version of the model was run to ensure that the results looked sensible and the baseline carbon emissions for 2008 were

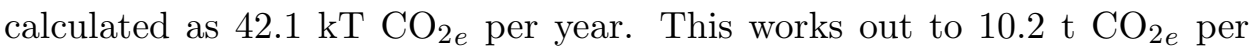
household, versus 12.6 t $\mathrm{CO}_{2 e}$ per household for the city as a whole. This 


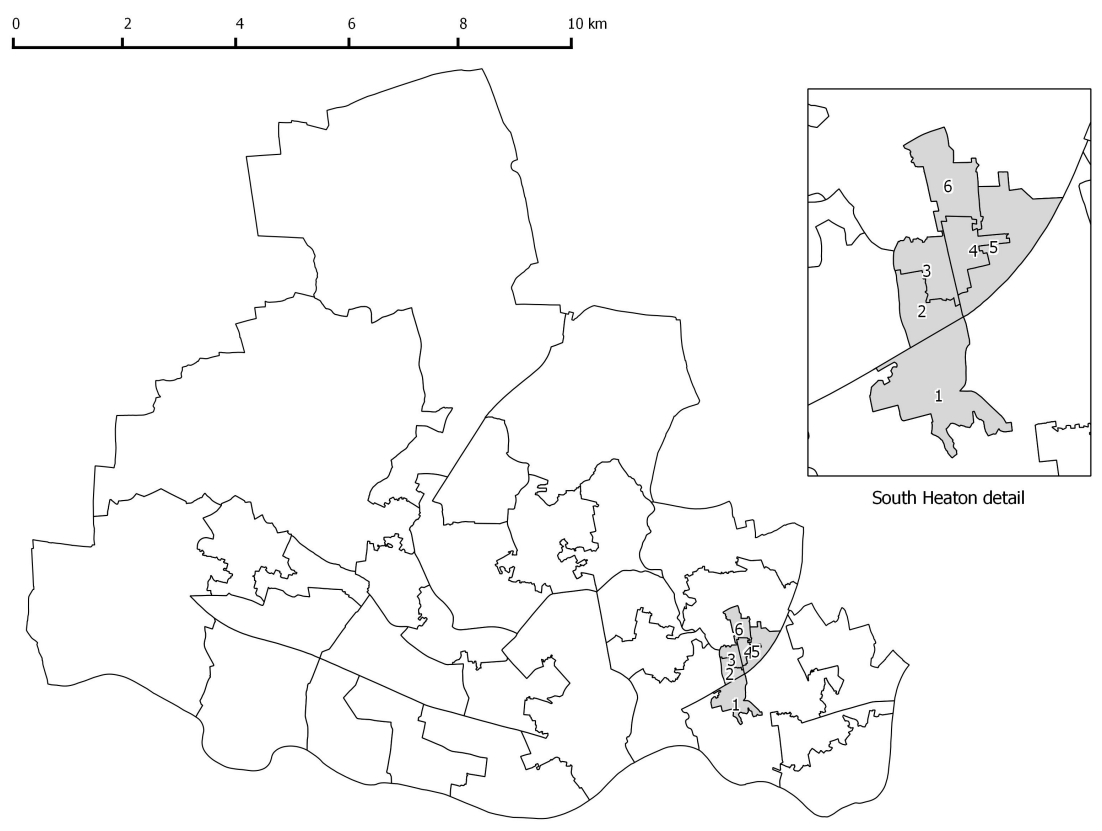

Figure 6: Map of Newcastle-upon-Tyne showing the South Heaton area.

difference is acceptable, as South Heaton is characterized by primarily residential housing and small commercial premises and therefore omits some of the larger commercial and industrial energy demands present at the wholecity scale.

Since this area has not been previously studied by other modelling tools, an explicit validation run was not performed. Nevertheless a forecasting model was configured and examined to ensure it produced reliable results. The key assumption was how to adjust the build rates for domestic and commercial technologies, from the values used at the whole city scale to something appropriate for the South Heaton area. Ultimately it was decided not to rescale these values (e.g. on a per capita basis) because, although this leads to a rapid transformation for the area, the scenario is plausible if the district was chosen as a demonstration or target area on behalf of the whole city. The model was also revised so that it had the choice to import district 
heating from a proposed energy centre in the nearby Byker district energy centre; this incurs a cost associated with building a $1 \mathrm{~km}$ heat pipe to link the South Heaton district.

Figure 7 shows the mix of technologies used to provide heat and electricity in the validation scenario. In the heat demand figure, we note the high penetration of efficiency measures in all zones but also observe three distinct modes of heat supply. In zones 4 and 6 , condensing gas boilers are largely maintained, while in zones 2 and 5 , there is a clear transition to domestic biomass boilers. Although zones 1 and 3 appear to share the use of district heating, it should be noted that this consists of two ultimate sources. In zone 1, the hypothesized Byker link is constructed and therefore the district heat is ultimately supplied by direct imports from the nearby energy centre. In zone 3 however, the district heat is provided by a local biomass CHP facility serving this zone only.

In the electricity figure, the black line shows the actual demand in each zone and excess amounts of electricity above this level are distributed to other zones to ensure supply equals demand. For example, zone 1 shows high levels of grid imports as this is where the model has chosen to make South Heaton's main connection to the external grid. The surplus above the black demand curve is then locally distributed to serve the deficits in the other zones. The model is not allowed to export any net electricity back to the grid from South Heaton as a simplifying assumption. Renewable electricity comes from domestic solar photovoltaics and behavioural changes that reduce electricity demand.

\subsubsection{Monte Carlo analysis}

In the whole city analysis, the sensitivity of seven input parameters was examined. The results showed that the growth rate of electricity demand and the maximum allowed penetration of CHP had the largest impact on the variability of key model outputs. In the present analysis, we explore 


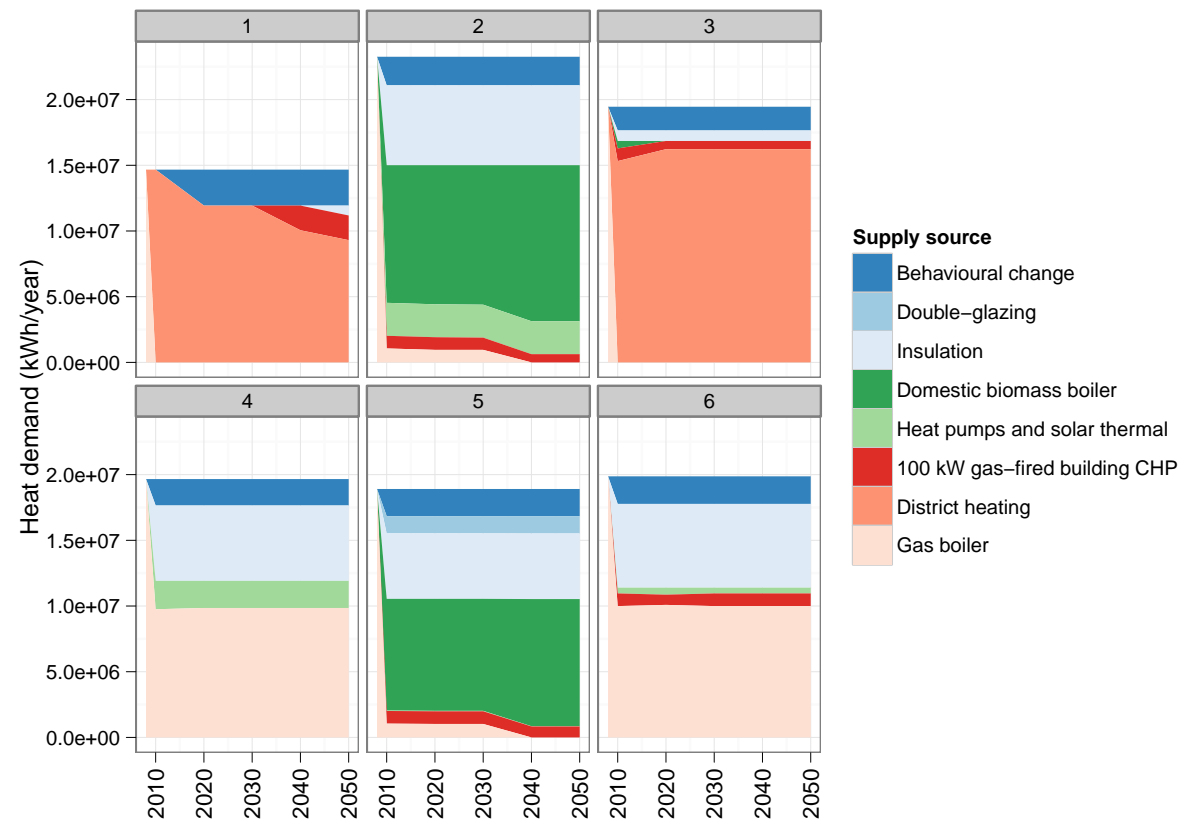

(a) Heat

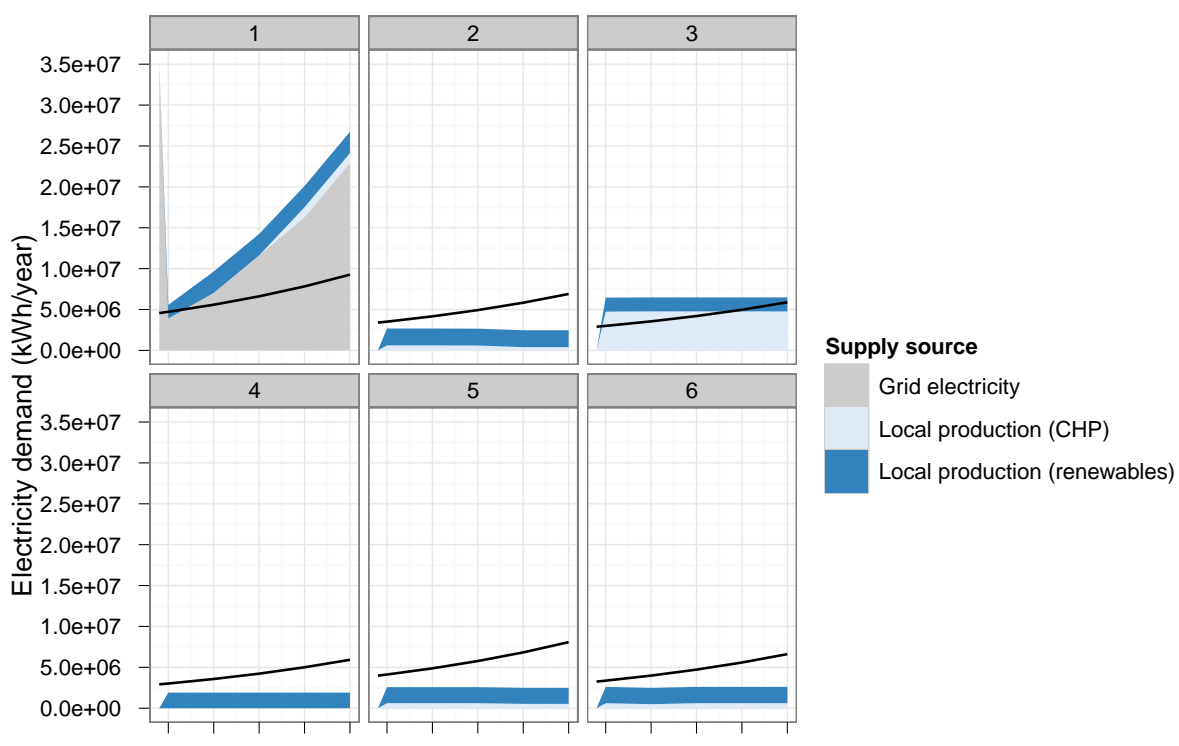

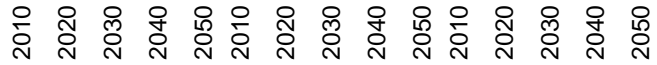

\section{(b) Electricity}

Figure 7: Provision of energy demand in the South Heaton validation case (2008-2050). Fossil-fuel sources are shown in red, renewable energy technologies in green, and efficiency measures in blue. The black curve in figure 2 (b) represents the demand in each zone. 
the variability associated with these two parameters through an uncertainty analysis. The parameter distributions were assumed to be $U(0,4) \%$ for the growth in electricity demand and $U(0,2.4) \mathrm{MW}$ for the maximum CHP penetration. We assume that the sensitivity of the five other variables will not change significantly for the South Heaton model configuration as three inputs are general financial parameters and the two build rate parameters are significantly larger than the size of the South Heaton challenge as discussed above. As the South Heaton model runs slower, owing to its spatial resolution, these simplifications facilitate a reduced Monte Carlo simulation of 200 runs.

While the results cannot be used for a full sensitivity analysis as presented above, they illustrate the variability of key model outputs and specifically the relative contributions of renewable energy, combined heat and power, and efficiency measures. First, Figure 8 shows the penetration of renewable energy in each of the zones, by sector, and illustrates that most of the commercial scale renewable energy comes from zones 2 and 3 (largely in the form of biomass CHP and large-scale solar thermal). The triangular patterns in zones 4 and 5 represent the model's indifference in allocating renewable energy capacity to 2020. Beyond that period, there is a much clearer pattern with zone 5 having a wider range of renewable energy penetrations depending largely on the rate of electricity demand growth.

Figure 9 shows the use of CHP within each zone. In zone 1, a consistently high penetration of CHP is seen but with very little variability. As discussed above, the ultimate source for the heat in this zone is the nearby Byker energy centre and so the level of use is unaffected by the changing constraint on the maximum amount of locally installed CHP. On the other hand, in zones 2 and 3, there is a wide range of variability depending on the level of the CHP penetration constraint.

Energy efficiency measures are a significant part of the overall strategy 


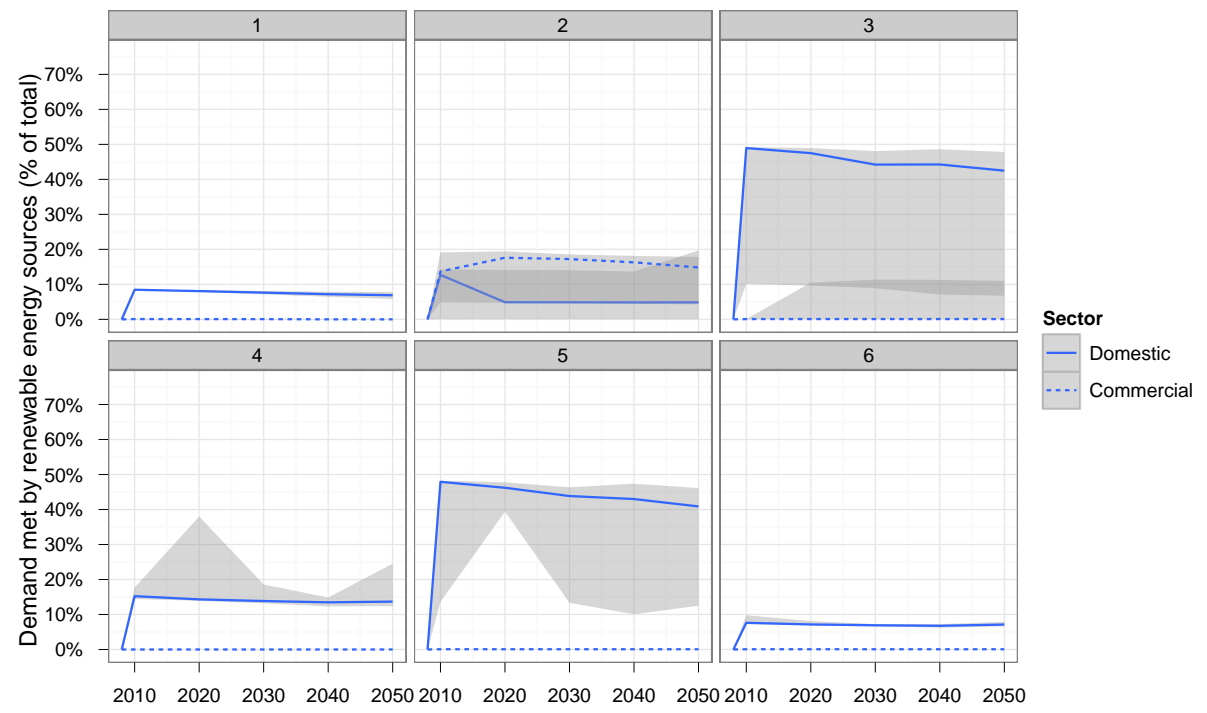

Figure 8: Distribution of renewable energy penetration for South Heaton scenarios. The shaded area represents the interquartile range and the lines represent the median result.

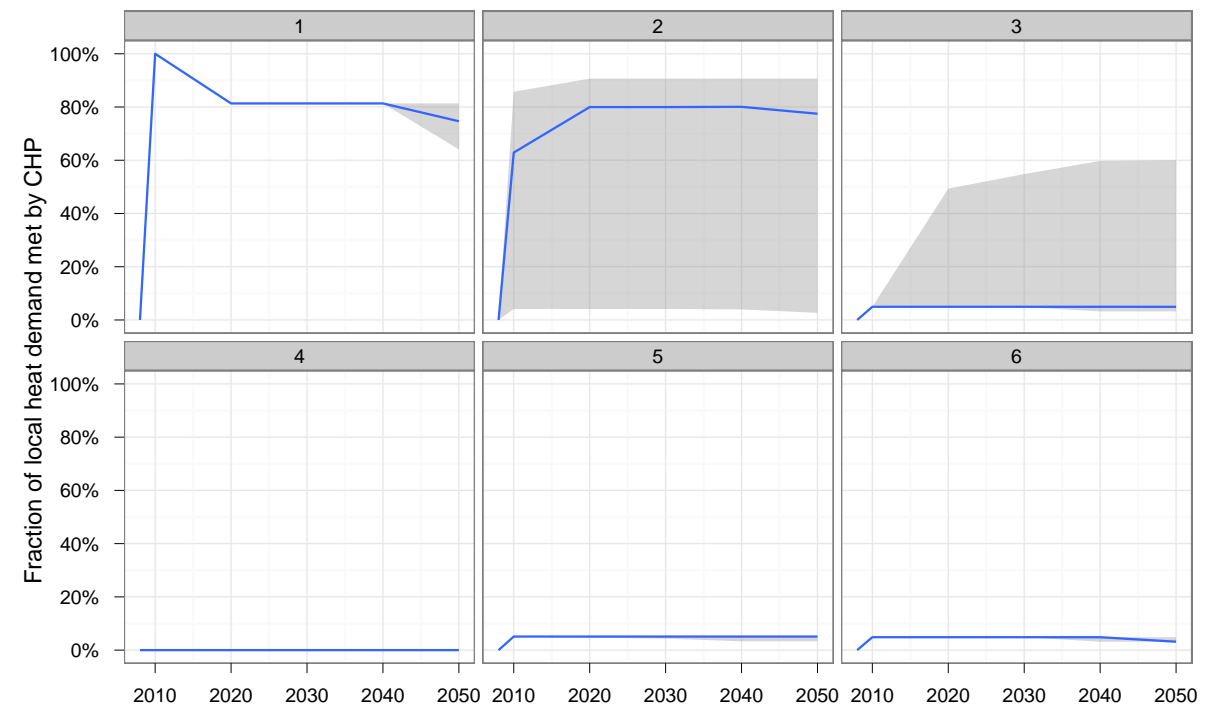

Figure 9: Use of combined heat and power for South Heaton scenarios. The shaded area represents the interquartile range with the median result. 
for South Heaton. In the whole city analysis above, a wide range of possible penetration rates for loft insulation, double-glazing, cavity wall and solid wall insulation were seen. When looking at South Heaton alone, the primary difference was that loft, cavity, and solid wall insulations were installed immediately, owing to the assumed possibility of a concerted effort in this one district. Again the HEED database provides details on existing rates of installation and house-type that enables one to estimate maximum penetration rates; this is shown in Figure 10. Note that only in zone 1, where heat is imported from the nearby Byker energy centre, is the installation of loft insulation left until the final period.

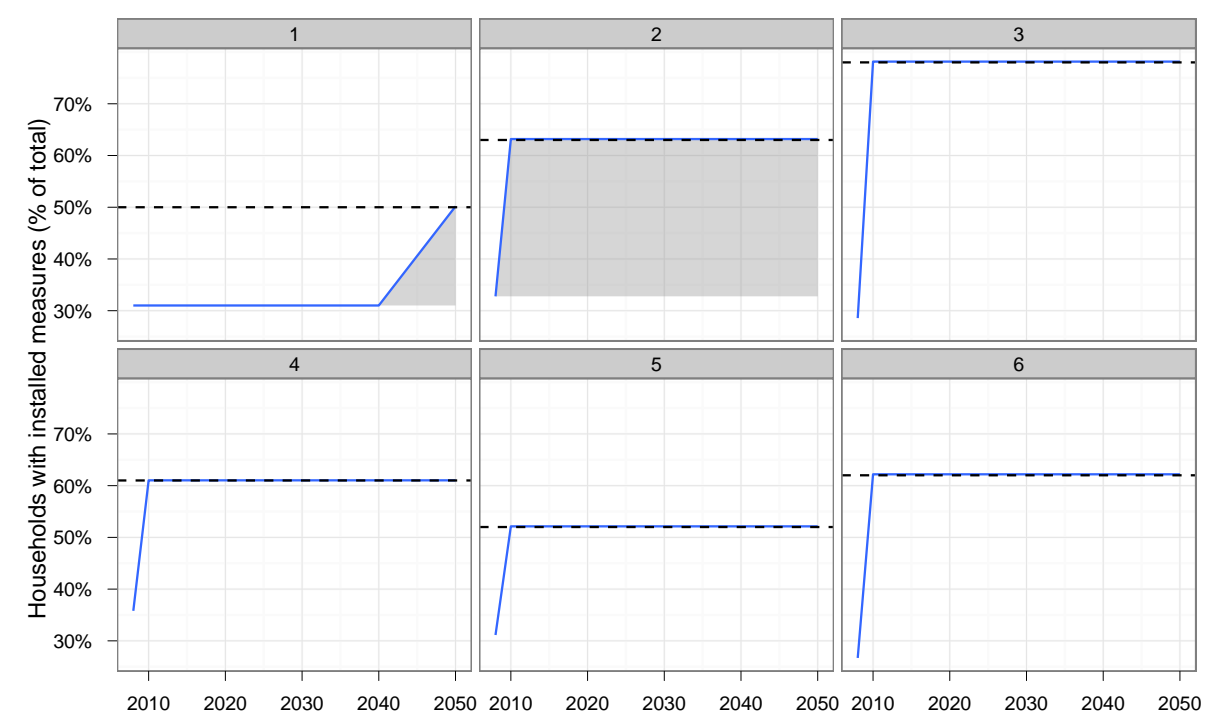

Figure 10: Installation rates for loft insulation in LLSOA zones within South Heaton. The shaded area represents the interquartile range with the median result; the dashed line represents the maximum penetration for each zone.

By applying the model to a spatially-resolved representation of South Heaton, we therefore see results broadly consistent with Newcastle's overall energy strategy. However unlike in the whole city case, these outputs are spatially-resolved with the figures revealing which zones should be tar- 
geted with what improvement measures and when. The analysis required additional information, in the form of more detailed data from the HEED database, but the results - for example, pin-pointing which zones should receive large investments for combined heat and power - can help local authorities to plan their interventions more precisely.

\section{Discussion}

In this section, we consider the implications of the results for urban energy and carbon modelling and policy. Specifically we comment upon the advantages and disadvantages of the present model, the role of uncertainty in policy planning, the need for spatial resolution in urban energy modelling, the need for good quality data, and areas for further improvement.

The results presented in this paper were created using a spatially and temporally resolved optimization model of urban energy systems. Such an approach is increasingly common in academic research, but for local authorities like Newcastle City Council, a bottom-up assessment is more popular wherein users select combinations of technologies to see if targets are met over short periods (i.e. a decade). The advantage of the optimization model is that it can ensure that policy constraints are met (e.g. a carbon emissions target), while pursuing a goal such as minimizing cost. Multiple technologies and their interactions can be considered as well, for example the links between increased penetrations of energy efficiency measures and the resulting reduced need for external heat supply. Similarly, NCC was interested in understanding the sequential aspects of a retrofitting strategy and the analysis confirmed their current thinking that energy efficiency measures are a priority and the full installation of loft, cavity and solid wall insulation should be pursued first.

A disadvantage of the TURN model is that one must take care to ensure that the problem is suitably defined so as to give a sensible result. For 
example, over the period 2010-2020, the Newcastle Energy Master Planning team noted that domestic wind would only be possible in 5-10 pilot cases and that medium-scale wind would not be actively promoted owing to limited site availability and planning restrictions. These technologies were therefore omitted from our modelling. On the other hand, ground and air source heat pumps were included but the council cautioned that its contribution may be limited in Newcastle due to the smaller size of local gardens. Similarly, although the seasonal temporal resolution of demands used here is an improvement on static energy planning models, a more detailed operational assessment would be needed to examine the likely performance of renewable energy technologies versus heat and power demands on a day-today basis. These issues highlight the importance of model calibration and validation, and the careful interpretation of results.

When planning over longer periods, current urban carbon modelling practice relies largely on single scenarios of the future. By contrast, we demonstrated how different assumptions about future conditions can be tested using Monte Carlo simulations to highlight a range of future outcomes. Using a set of representative uncertain inputs, key parameters with significant impact on the model results were identified. The growth rate of electricity demand is one such example with the results indicating that growth rates should be kept below $4 \%$ if emissions targets are to be met. This was an unexpected result for the NCC climate change team, who had not explicitly modelled this variable before. Potential policy responses to address this issue might include local information campaigns, the installation of smart meters, and engagement with electricity suppliers to introduce tariffs with higher marginal costs in order to suppress excessive consumption. ${ }^{2}$ More generally, Figures 3, 5 and 8-10 clearly illustrate the range of

\footnotetext{
${ }^{2} \mathrm{UK}$ domestic electricity tariffs typically have a higher per $\mathrm{kWh}$ rate for a given initial consumption per year (e.g. $900 \mathrm{kWh}$ per year) and then a lower rate, e.g. $50 \%$ of the initial
} 
possible outcomes and allow policy makers to draw robust conclusions, for example, regarding the timing of energy efficiency measures.

A key motivation for this research was to examine how city-wide carbon emissions targets can be translated into spatially-resolved recommendations. Spatial disaggregation is intrinsically linked to the area-based delivery of retrofitting measures and such evidence is vital to the development of funding bids for targetted low carbon community schemes. The South Heaton results demonstrated the variations in renewable energy, combined heat and power, and efficiency installations on a zone-by-zone basis, enabling the council to glimpse the unique character of each zone and target appropriate intervention measures. This spatial disaggregation is particularly relevant for technologies such as CHP. For example, while the general solution for Newcastle featured a significant amount of CHP use, the analysis of South Heaton allowed this to be interpreted in light of local geography and spatially-determined costs (e.g. for pipe networks, see also Figure 9). The result means that general advice to "use CHP" can be converted into specific recommendations such as "connect zone 1 to the Byker energy centre" and "explore the possibility of using smaller local CHP systems in zones 2 and 3". This type of analysis could provide the council with evidence to, for example, develop a funding proposal to retrofit zone 1 with a district heating system utilizing the Byker link. The South Heaton results also showed that a rapid and substantial change in a local energy system is possible, if sufficient effort and resources are committed (particularly for energy-efficiency measures).

Regardless of the modelling method chosen, it is important to have good quality input data. Using data from the UK HEED database provides a good starting point but the issue of data quality becomes more significant

unit cost, for consumption beyond that threshold. 
as spatial disaggregation increases. In South Heaton, we inferred maximum levels of insulation penetration from HEED and the model chose to install as much as possible in the first period for most zones. If these data were found to be significantly different, the resulting energy demands might be higher or lower and other technologies would have to become part of the energy solution. In such a case, where a lack of spatial aggregation means that discrepancies are not smoothed out over larger areas, it is very important that local authorities develop and maintain high quality descriptions of their building stocks.

While the TURN model therefore provides valuable insights beyond a bottom-up assessment tool like VantagePoint, there are many ways in which it could be improved. For example, although we explicitly modelled technology installation and demolition, there was no consideration of technology lifetimes, e.g. replacing boilers after $x$ years. This assumption is fine for short term analyses as in the calibration or 2020 validation studies, but when estimating energy system structure to 2050, technology replacement and the changes in costs associated with technological advances and learning are likely to be significant. Another area for further work is the costing of energy networks within the model. For example, although the model includes a spatial representation of a district heating system, it is stylized and only considers the pipe distance from zone-to-zone; the costs of "last mile" distribution within a zone are not explicitly modelled and must be assumed.

\section{Conclusion}

This paper has presented a method for developing urban energy and carbon strategies and explored how it might be used by local authorities. Using the example of Newcastle-upon-Tyne, we demonstrated how the local authority currently relies upon bottom-up assessment tools to develop energy strategies for meeting greenhouse gas emissions targets. These tools require 
the user to build a scenario that meets emission reduction targets, with the disadvantage that interactions between technologies, spatial disaggregations, and over-arching policy goals cannot be easily handled. In contrast, the optimization based modelling approach described here lets these factors be considered, allowing detailed energy solutions that meet carbon targets and comply with broad policy ambitions like minimizing cost.

After validating the model for the case of Newcastle, we compared the results of an analysis of Newcastle as a whole and the South Heaton district in particular. Using Monte Carlo simulation techniques, we were able to identify the energy system solutions that are consistently present under a range of parameter scenarios. The results highlighted the need to control the growth of electricity demand, the installation of efficiency measures as soon as possible, and the use of domestic renewable energy technologies, combined heat and power, and decarbonized grid electricity to meet the remaining demands.

The method presented here has significant advantages for local authorities seeking to plan the evolution of their urban energy systems, in particular offering spatially-resolved evidence to help the development of low carbon community schemes. There are a number of challenges, in terms of data availability and representing local circumstances accurately within the model, but these initial results suggest that the technique offers new capabilities and insights to local authorities.

\section{Acknowledgments}

The financial support of BP via the Urban Energy Systems project at Imperial College London and Newcastle University is gratefully acknowledged. Thanks to Nouri Samsatli and Nilay Shah at Imperial College for their contributions in developing an earlier version of the TURN model. The input, guidance and advice of Newcastle City Council climate change and 
energy master planning teams is fully appreciated.

\section{References}

Betsill, M., Bulkeley, H., 2007. Looking back and thinking ahead: A decade of cities and climate change research. Local Environment 12:5, 447-456.

Bintliff, E., Kashiwagi, A., Liu, M., Margolis, M., Underwood, A., 16-23 April, pp 76-79 2007. Cities of virtue. Newsweek.

Bruckner, T., Morrison, R., Handley, C., Patterson, M., 2003. Highresolution modeling of energy-services supply systems using decco: Overview and application to policy development. Annals of Operations Research 121, 151-180.

Bulkeley, H., Betsill, M. M., 2005. Rethinking sustainable cities: Multilevel governance and the urban politics of climate change. Environmental Politics 14 (1), 42-63.

C40 Cities, 2011. Climate leadership group. http://live.c40cities.org/, last accessed 9 November 2011.

Carbon Descent, 2012. VantagePoint - carbon scenario planning tool. http://www . carbondescent.org.uk/pages/vantage-point.html.

CCC, 2010. Committee on Climate Change: Path to 2050.

URL http://www. theccc.org.uk/carbon-budgets/path-to-2050

Celik, A. N., Muneer, T., Clarke, P., Jan 2007. An investigation into micro wind energy systems for their utilization in urban areas and their life cycle assessment. Proceedings of the Institution of Mechanical Engineers, Part A: Journal of Power and Energy 221 (8), 1107-1117.

Corfee-Morlot, J., Cochran, I., Teasdale, P.-J., 9-10 October 2008. Chapter 7. Cities and Climate Change: Harnessing the potential for local action. 
In: Competitive Cities and Climate Change. OCDE, Milan, Italy, pp. $78-105$.

Dawson, R., 2007. Re-engineering cities: a framework for adaptation to global change. Philosophical Transactions of The Royal Society. A 365 (365), 3085-3098.

DECC, June 2011a. Microgeneration strategy. Tech. rep., Department of Energy and Climate Change (DECC).

DECC, 2011b. MLSOA and LLSOA electricity and gas.

URL http://www.decc.gov.uk/en/content/cms/statistics/energy_stats/regional/electr

DECC, 2011c. NI 186: Per capita reduction in CO2 emissions in the local authority area.

URL http://www.decc.gov.uk/en/content/cms/statistics/indicators/ni186/ni186.aspx

Dhakal, S., Shrestha, R. M., 2010. Bridging the research gaps for carbon emissions and their management in cities. Energy Policy 38 (9), 47534755 .

EST, 2011. Home Energy Efficiency Database (HEED).

URL http://heed.est.org.uk/

Girardin, L., Marechal, F., Dubuis, M., Calame-Darbellay, N., Favrat, D., Feb 2010. Energis: A geographical information based system for the evaluation of integrated energy conversion systems in urban areas. Energy $35(2), 830-840$.

HM Government, July 2009. The UK Low Carbon Transition Plan: National strategy for climate and energy. Tech. rep., Department of Energy and Climate Change (DECC).

Hong, S. H., Gilbertson, J., Oreszczyn, T., Green, G., Ridley, I., Jun 2009. A field study of thermal comfort in low-income dwellings in England before 
and after energy efficient refurbishment. Building and Environment 44 (6), $1228-1236$.

IEA, 2008. World Energy Outlook. International Energy Agency.

IPCC, 2007. IPCC Fourth Assessment Report on Climate Change: Synthesis Report. Tech. rep., IPCC.

Kampf, J., Robinson, D., Apr 2007. A simplified thermal model to support analysis of urban resource flows. Energy and Buildings 39 (4), 445-453.

Kannan, R., Strachan, N., Pye, S., Anandarajah, G., Balta-Ozkan, N., 2010. Appendix EH-III: List of electricity and heat generation technologies. http://www .ukerc.ac.uk/support/tiki-index.php?page=ES_MARKAL_Documentation_2010.

Keirstead, J., Jennings, M., Sivakumar, A., accepted. A review of urban energy system models: approaches, challenges and opportunities. Renewable and Sustainable Energy Reviews.

Keirstead, J., Samsatli, N., Shah, N., Weber, C., in press. The impact of CHP (combined heat and power) planning restrictions on the efficiency of urban energy systems. Energy.

Keirstead, J., Schulz, N. B., 2010. London and beyond: Taking a closer look at urban energy policy. Energy Policy 38 (9), 4870-4879.

Kikegawa, Y., Genchi, Y., Kondo, H., Hanaki, K., Jun 2006. Impacts of city-block-scale countermeasures against urban heat-island phenomena upon a building's energy-consumption for air-conditioning. Applied Energy 83 (6), 649-668.

Mavrogianni, A., Davies, M., Batty, M., Belcher, S., Bohnenstengel, S., Carruthers, D., Chalabi, Z., Croxford, B., Demanuele, C., Evans, S., et al., 
Jan 2011. The comfort, energy and health implications of London's urban heat island. Building Services Engineering Research and Technology $32(1), 35-52$.

NCC, 2011. Newcastle's Climate Change Strategy and Action Plan. www.newcastle.gov.uk/environment/environment/climate-change.

ONS, 2011. Super output areas: introduction.

URL http://www.neighbourhood.statistics.gov.uk/dissemination/Info.do?page=aboutne

Pohekar, S., Aug 2004. Application of multi-criteria decision making to sustainable energy planning: A review. Renewable and Sustainable Energy Reviews 8 (4), 365-381.

Saltelli, A., Ratto, M., Andres, T., Campolongo, F., Cariboni, J., Gatelli, D., Saisana, M., Tarantola, S., 2008. Global Sensitivity Analysis: The Primer. Wiley Blackwell.

Samsatli, N., Keirstead, J., Shah, N., submitted. A generic MILP model for the design of urban energy systems. Energy Conversion and Management.

Shackley, S., Fleming, P., Bulkeley, H., March 2002. Area-based carbon emission reduction: A scoping study. Tech. rep., Prepared for the Sustainable Development Commission by the Tyndall Centre for Climate Change Research.

Shimoda, Y., Yamaguchi, Y., Okamura, T., Taniguchi, A., Yamaguchi, Y., Jun 2010. Prediction of greenhouse gas reduction potential in Japanese residential sector by residential energy end-use model. Applied Energy 87 (6), 1944-1952.

Stern, N., 2006. Stern review on the economics of climate change. executive summary. Tech. rep., HM Treasury, London. 
Sugihara, H., Komoto, J., Tsuji, K., May 2004. A multi-objective optimization model for determining urban energy systems under integrated energy service in a specific area. Electrical Engineering in Japan 147 (3), 20-31.

Taherian, H., Rezania, A., Sadeghi, S., Ganji, D., Jan 2011. Experimental validation of dynamic simulation of the flat plate collector in a closed thermosyphon solar water heater. Energy Conversion and Management $52(1), 301-307$.

UK Government, November 2008. Climate Change Act. http://www. legislation.gov.uk/ukpga/2008/27/contents.

Wei, Y., Guo-qiang, Z., Xiao, W., Jing, L., San-xian, X., Sep 2010. Potential model for single-sided naturally ventilated buildings in China. Solar Energy 84 (9), 1595-1600. 